\title{
A Kinematic WAVE MODEL OF GLACIER SURGES
}

\author{
By Andrew C. Palmer \\ (Engineering Department, Cambridge University, Cambridge, England)
}

\begin{abstract}
Aвstract. The existing theory of kinematic waves on glaciers does not account for self-induced instability of the flow, or for surges which are not the result of external disturbances. Surges do however have much in common with kinematic waves. Unstable behaviour of glaciers can be explained by a straightforward modification of kinematic wave theory. In this modification the relation between the ice flow and the ice depth is not the same when the ice is accelerating as when it is slowing down. A similar effect has previously been shown to explain observed instabilities in the flow of highway traffic, a phenomenon which is otherwise adequately described by a simple kinematic wave theory.

RÉsumé. Un modèle d'onde cinématique pour les foirages glaciaires. Les théories existantes sur les ondes cinématiques sur les glaciers ne rendent pas compte de l'instabilité auto-induite de l'écoulement, ou des crues qui ne sont pas le résultat d'une perturbation externe. Le comportement instable des glaciers peut être expliqué par une modification linéaire de la théorie de l'onde cinématique. Dans cette modification la relation entre l'écoulement de la glace et son épaisseur n'est pas le même lorsque le mouvement de la glace vers l'aval est accéléré ou retardé. Un effet analogue a déjà été mis en évidence pour expliquer l'instabilité observée dans l'écoulement du trafic routier, un phénomène qui autrement serait bien décrit par la simple théorie des ondes cinématiques.

Zusammenfassung. Eine kinematische Welle als Modell für Gletscherausbrüche. Die bestehende Theorie von kinematischen Wellen auf Gletschern berücksichtigt nicht selbstinduzierte Instabilität des Fliessens oder Gletcherausbrüche, die nicht durch äussere Störungen ausgelöst wurden. Gleichwohl haben Gletscherausbrüche vieles mit kinematischen Wellen gemein. Instabiles Verhalten von Gletschern kann durch eine einfache Modifikation der Theorie der kinematischen Welle erklärt werden. In dieser Modifikation ist das Verhältnis zwischen Eisfluss und Eistiefe bei wachsender Geschwindigkeit des Eises verschieden von dem bei abnehmender Geschwindigkeit. Mit einem ähnlichen Effekt konnten auch beobachtete Instabilitäten im Fliessen des Strassenverkehrs erklärt werden, einem Phänomen, das im übrigen hinreichend durch eine einfache Theorie der kinematischen Welle beschrieben wird.
\end{abstract}

\section{INTRODUCTION}

Many of the observed features of the flow of glaciers can be adequately described by a simple kinematic wave model. Such a model does not account for the instability in an initially apparently steady flow which later develops into a surge. Many observations of the behaviour of highway traffic flow are similarly found to be quite consistent with a kinematic wave model, and yet traffic flow sometimes develops instabilities which have much in common with glacier surges. This paper explores the application to glaciers of a modification to simple kinematic wave theory which has been shown to explain instabilities in traffic.

\section{Kinematic WAVES AND INSTABILITIES OF HighWAY TRAFFiC}

Kinematic wave theory is explained in detail in a paper by Lighthill and Whitham ( $1955[\mathrm{a}],[\mathrm{b}])$. Nye (1960, I963) has discussed its application to glaciers, and recent developments have been discussed by Paterson (1969). The central idea is very simple. Imagine a process in which some substance flows in a single stream in a single direction, and suppose the flow at some point on the stream to be completely described by the flow rate $q$ (the amount of substance that passes a fixed point in unit time) and the concentration $k$ (defined so that the amount of substance in a short length of stream $\mathrm{d} x$ is $k \mathrm{~d} x$ ). Denote time by $t$ and distance by $x$. If the substance is neither created nor destroyed within the stream, then it follows from conservation of the amount of substance that

$$
\frac{\partial q}{\partial x}+\frac{\partial k}{\partial t}=o
$$

If $q$ is a function of $k$ alone, and $c=\mathrm{d} q / \mathrm{d} k$, then Equation (I) becomes

$$
\frac{\partial q}{\partial x}+\frac{\mathrm{I}}{c} \frac{\partial q}{\partial t}=\mathrm{o}
$$


and the solutions to this first-order partial differential equation are kinematic waves moving down-stream with velocity $c$. Of course $c$ will not in general be constant, but will instead be a function of $k$, so that the velocities of the waves will not be independent of their amplitudes.

Kinematic waves consistent with such a model have frequently been observed on real glaciers, but it has been usual to make a careful distinction between surges and kinematic waves. Surges do however have some of the features of kinematic waves. Meier and Post ( 1969 ) describe for instance a surge on the Tikke Glacier in the Alsek range of British Columbia. They looked for recognizable points on the surface of the glacier and plotted the positions of these points in successive years onto maps of the glacier. Independently they each year identified the zone of rapid flow. Their data has been replotted in Figure $\mathrm{I}$, in which the ordinate is time (identified only by the year) and the abscissa is distance, measured down the centre-line of the glacier from an arbitrary origin. Solid lines represent trajectories of points on the ice; the less steeply a line slopes, the faster the motion of the point it represents. The rapid flow zone is bounded by the two dashed lines. Though few trajectories are available,

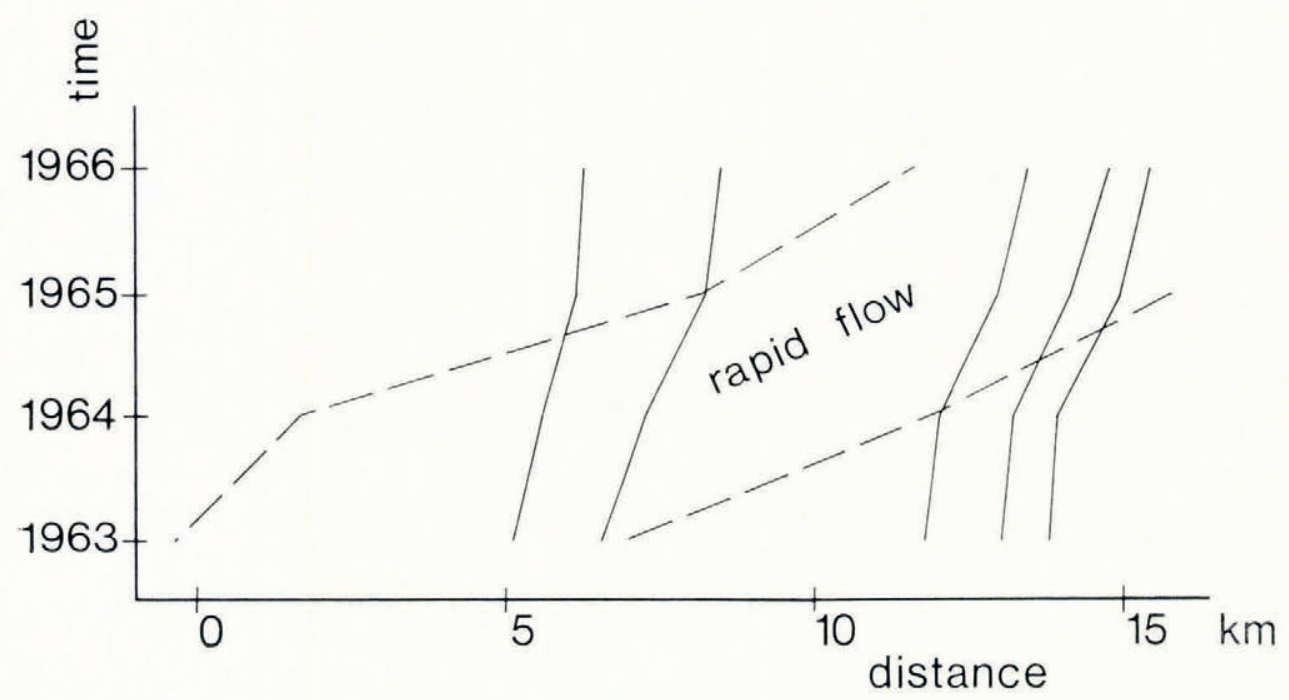

Fig. I. Wave and particle trajectories in a surge on the Tikke Glacier (Alsek range, British Columbia). Data from Meier and Post (1969).

the diagram does suggest that the rapid flow zone is preceded by an acceleration wave (the lower dashed line), so that as the wave passes a point on the ice the velocity of that point increases quite rapidly by a factor of the order of 4 . The zone of rapid flow is followed by a deceleration wave moving at about the same speed as the acceleration wave, and as it passes the ice returns to its original velocity. The velocity of the acceleration and deceleration waves, which we might call the surge velocity, is about five times the velocity of the ice behind the acceleration wave.

It seems clear that this surge does show at least some of the characteristics of a kinematic wave. The mathematical model of Equation (I) does not however explain how a surge can originate in a glacier apparently in a steady state, or rather only does so if there is some external disturbance which modifies the glacier's mass balance.

Can there be self-induced instability which is not the consequence of an external disturbance? Such an instability is known to occur in a quite different kind of flow, that of highway traffic, even though many of the observed features of traffic flow can be explained by a simple kinematic wave theory like the one described above. In this simple theory (Lighthill and 
Whitham, I955[b]) the flow-concentration relation for traffic has the general form illustrated in Figure 2. Traffic is thought of as a fluid continuum, $k$ is the number of vehicles in unit length of road, and $q$ is the rate at which they pass a fixed point. If the density of traffic is small each vehicle moves with its free speed, the speed it would have if it were entirely alone, and this is the slope of the graph at the origin. If the density of traffic is very high, it comes to a complete stop, and the flow is zero. In between there is a density at which the flow is a maximum. The graph is easier to interpret if it is replotted in such a way that one can at the same time think of the behaviour of a single vehicle, and this is done by plotting the velocity

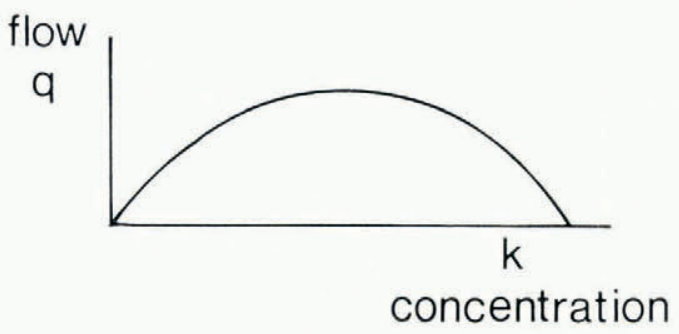

Fig. 2. The relation between flow and concentration of highway traffic: simple theory (Lighthill and Whitham, 1955[b]).

$q / k$ against the reciprocal of the concentration $\mathrm{I} / k$, the headway between vehicles (Fig. 3 ). The kinematic wave velocity corresponding to a point on the curve is then the intercept on the velocity axis of the tangent from the point. By considering the effects of a small perturbation, it can be shown that traffic flow governed by this model is always stable: a small disturbance only gives rise to small and localized effects. Real traffic, however, is sometimes unstable. The best-known example is that of traffic in the Holland Tunnel in New York

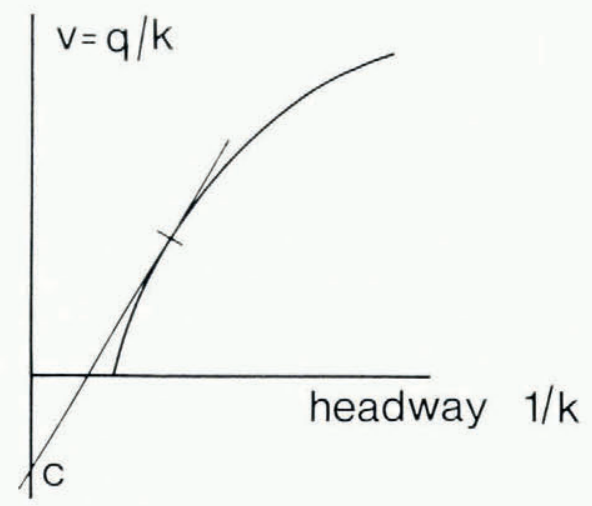

Fig. 3. The relation between velocity and headway for highway traffic: simple theory (Lighthill and Whitham, I955[b]).

(Greenberg and Daou, I960), an ideal case for the application of the simple theory because there are no intersections and overtaking is not allowed. In certain rush-hour conditions it happens that a small disturbance in the flow appears to originate near the beginning of the upgrade out of the tunnel. The disturbance grows rapidly, and soon cars are coming to a complete stop for periods of the order of a minute, even though flow out of the tunnel is absolutely steady. A pulsating flow develops, with a period of the order of four minutes.

An explanation of this phenomenon is due to Newell (1962, r965). He suggested that the velocity-headway relation is less simple than that of Figure 3, because streams of vehicles 
behave differently when they accelerate and when they decelerate. In his model, if the traffic were continuously accelerating the velocity-headway relation would follow the lower curve of Figure 4 but if instead it were continuously decelerating it would follow the upper curve. If the velocity increased until point I was reached, and then decreased, the point representing the velocity and headway would follow a connecting curve through point $\mathrm{I}$ until it reached the continuous deceleration curve at 2 , and would from then on follow that curve. There is a whole family of such connecting curves, one connecting each point on the acceleration curve to a point on the deceleration curve. If somewhere on such a connecting curve acceleration began again, the operating point would return along the curve.

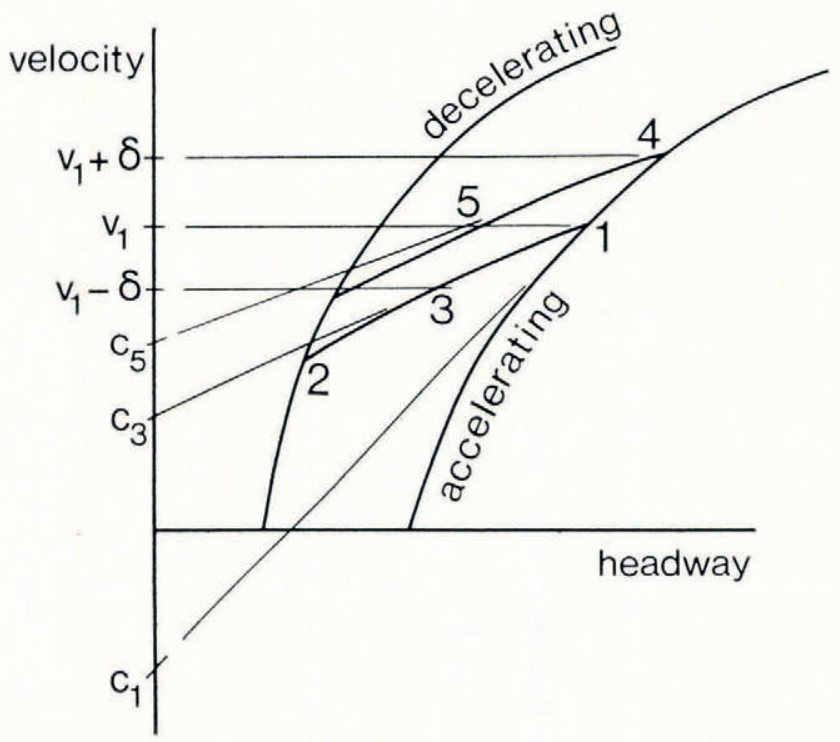

Fig. 4. Velocity-headway relation for highway traffic: modified theory (Newell, 1962).

Consider the effect of small fluctuations in velocity. Suppose the state is at point $\mathrm{I}$, on the acceleration curve, and at some point in the traffic flow there is a sudden reduction in speed from $v_{\mathrm{I}}$ to $v_{\mathrm{I}}-\delta$ followed by an acceleration back to $v_{\mathrm{I}}$. The state retreats along the connecting curve to 3 and then returns to $\mathrm{I}$. The initial decleration produces a deceleration wave, moving with the velocity $c_{3}$ corresponding to the intercept of the tangent from the connecting curve from I; the subsequent acceleration produces an acceleration wave moving with the same velocity. The two waves travel together, and the disturbance is transmitted but not magnified.

An acceleration to $v_{1}+\delta$ followed by a deceleration to $v_{1}$ has a qualitatively different effect. Acceleration takes the operating point to 4 , and deceleration takes it back to 5 along the connecting curve through 4 . Two waves set out: an acceleration wave moving with velocity $c_{1}$ (corresponding to the tangent to the acceleration curve) and a deceleration wave moving with velocity $c_{5}$ (corresponding to the tangent to the connecting curve). The two waves have quite different velocities, and in fact in this case the acceleration wave moves upstream and the deceleration wave down-stream. The effect is clear if one looks at trajectories of points in the stream (Figure 5), which can be thought of as single vehicles. Point A represents the initial disturbance, a sudden rise in speed followed almost at once by a return to the original speed. At the acceleration wave, indicated by a dashed line, velocities increase by $\delta$, and at the deceleration wave velocities decrease by $\delta$. Everywhere within the triangular 
region between the two waves the acceleration "signal" has arrived but the deceleration signal has not, and so, even though the original disturbance was very brief, it produces a wider and wider region in which cars remain at the higher speed for longer and longer intervals. Furthermore, all the points within the triangular region are represented by a point on the acceleration curve (point 4) and so the region is in the same kind of state as it was initially in point $\mathrm{I}$. Another upward fluctuation in speed, however brief, will produce a region moving at a still higher speed, and this drift to higher velocities can continue until limited by the changing shape of the curves. Because the effects of upward and downward fluctuations in speed do not cancel each other, the original flow of traffic in state I was unstable, and the cumulative effect of the fluctuations is a marked alteration in the flow, no matter how small the individual fluctuations are.

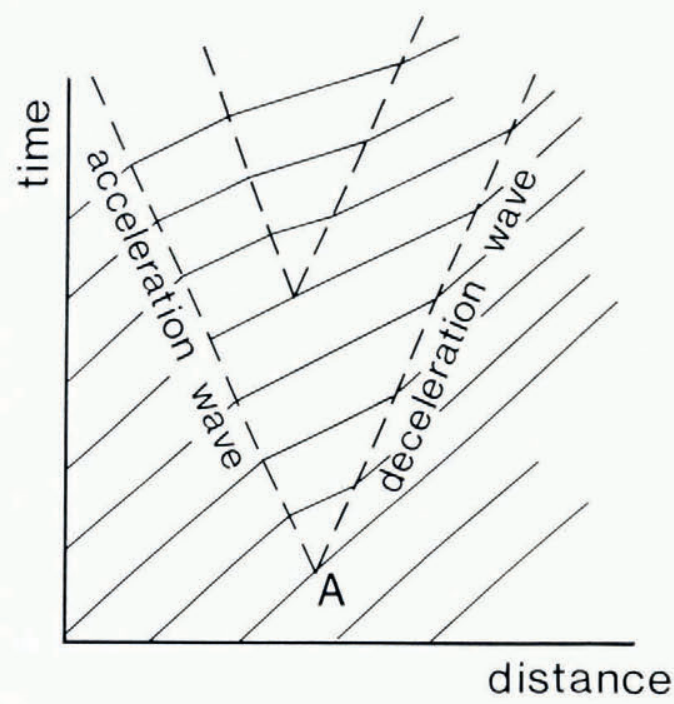

Fig. 5. Vehicle trajectories in unstable traffic flow.

Newell was able to show that this kind of instability could account for traffic pulses in the Holland tunnel, and for the success of traffic control measures that had empirically been found to suppress pulsating flow. Similar behaviour occurs at points on the deceleration curve, which is why traffic can come to a stop, and why cyclic flow can occur. There is some observational evidence that velocity-headway relationships are indeed different during acceleration and deceleration.

\section{SURGES ON GLAGIERS}

Could an effect of this kind account for glacier surges?

Suppose the relation between flow and depth of ice were like the one illustrated in Figure 6. If the flow were continuously accelerating, the relation would follow the lower curve, and if it were decelerating it would follow the upper curve. If it had been accelerating but stopped doing so and began to decelerate, then it would follow a connecting curve back to the continuous deceleration curve, and then would continue down that curve.

Idealize the glacier as an accumulation zone (in which ice is deposited at a constant rate) connected to an ablation zone (from which ice is removed at a constant rate equal to the accumulation rate) by a third zone in which there is neither accumulation nor ablation. 
Imagine that as long as the flow regime is altering only slowly, between surges, all the points in this third zone of the glacier are represented by a single point on the flow-depth diagram, so that $q$ and $h$ are the same everywhere. Suppose that the flow rate has been slowly increasing, and that the state of the glacier has reached a point on the acceleration curve.

A small downward fluctuation in the flow, followed by a return to the original flow, would send out two waves, with almost the same velocities. Depending on the detailed shape of the connecting curve through the initial state, it might be that one wave would develop into a shock and annihilate the other, or that both would continue to travel down the glacier, but in any case the effects of such a downward fluctuation in speed would be small. Consider, on the other hand, the effects of a small upward fluctuation in flow followed by a deceleration back to the original flow. Exactly as in the traffic flow case, such a disturbance will cause two waves to set out, and they will move with markedly different velocities. The acceleration wave will have a velocity corresponding to the gradient of the "accelerating flow" curve at the initial state point, whereas the deceleration wave will have the much smaller velocity corresponding

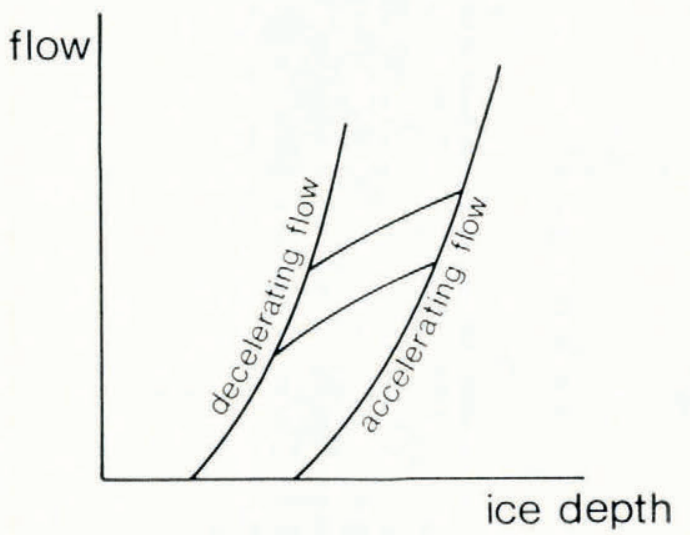

Fig. 6. A conjectural relation between ice flow and ice depth in a glacier.

to the gradient of the connecting curve through the same point. Between these two waves there will be a steadily growing region in which the ice is moving more rapidly. Within that region the state is again at a point on the "accelerating flow" curve, and so the same kind of fluctuation can occur repeatedly, producing regions with still higher velocities. The original flow regime when the operating point reached the accelerating flow curve was unstable, in the sense that the effects of small random fluctuations accumulate and lead to quite a different flow regime.

Within the growing accelerated region each of the acceleration waves, individually small in magnitude, has a velocity proportional to the gradient of the accelerating flow curve at the state corresponding to the ice depth at that wave. The accelerating flow curve has a gradient which increases with increasing ice depth, which implies that the acceleration waves formed by fluctuations occurring later in the process will have higher velocities than acceleration waves originating earlier, and will therefore tend to catch them up. At the front of the accelerated region the waves will coalesce, to form an acceleration shock in which the ice velocity increases rapidly. This seems consistent with observations of surges. The speed with which this shock advances cannot be determined without detailed knowledge of the shape of the flow-depth curve, but the velocity of the acceleration shock between two points on the accelerating flow curve will correspond to the gradient of a secant drawn between the two points. This will be larger than the ice velocity behind the shock, which corresponds to the gradient of a line from 
the origin to the point further up the accelerating flow curve. This is again consistent with the observations described in Figure I, and does indeed suggest that records like those of Meier and Post (r969), which are relatively easy to obtain, might be used to construct the relation between the flow and the ice depth.

The implication of this model is that disturbances only move down-stream, and not upstream, and so flow out of the accumulation zone will not be affected. Within the accelerated region the drift to higher flows will raise the flow above the supply from the accumulation zone, and large volumes of ice will move down-stream into the ablation zone. If this picture is correct, and the flow at a single point in the glacier were to be plotted against the depth at that point, at different times during the surge cycle, the relation between the two might be expected to be like the loop cycle illustrated in Figure 7, the loop being described in a counterclockwise direction. Different points in the glacier would not of course be in phase. Unfortunately there is no published field data reporting observations of both depth and velocity at different stages of a surge, and this makes it impossible to examine the validity of this conjecture.

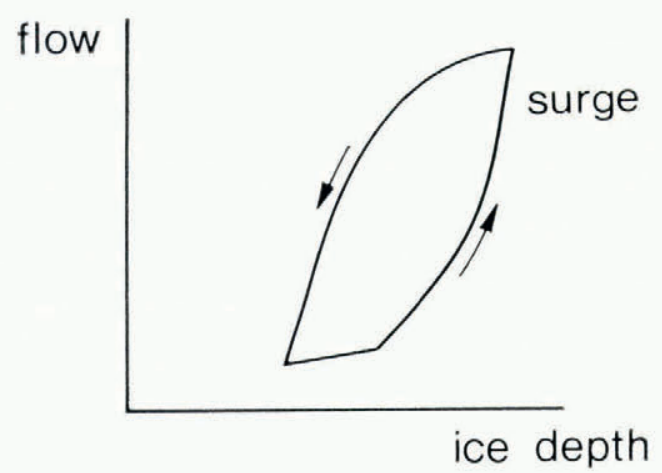

Fig. 7. The relation between flow and depth at a fixed point at different times during a surge cycle.

One has of course to ask why the flow-depth relationship should resemble Figure 6 . This must depend crucially on basal sliding theory, which is controversial and very far from completely understood. It does seem consistent with a Lliboutry model in which an important part is played by bodies of water in cavities beneath the glacier. If the flow alters rapidly, these cavities will take some time to respond and readjust themselves towards a new steady state. There will be a memory effect by which basal sliding depends not only on present velocities and basal shear stresses but on their recent history, and behaviour in steadily accelerating flow will then be different from that of decelerating flow.

In the argument outlined above no account has been taken of the diffusion effect present in a less severely idealized version of the kinematic wave model (Weertman, I958; Nye, i96o). If this is included, Equation (2) becomes

$$
\frac{\partial q}{\partial x}+\frac{\mathrm{I}}{c} \frac{\partial q}{\partial t}=D \frac{\partial^{2} q}{\partial x^{2}}
$$

where $D$ is a positive diffusion coefficient. The added term accounts for the effect of the added term on the flow rate, which is then not just a function of $q$ but also a function of $\partial q / \partial x$. A hump in the glacier surface will then tend to diminish in size as time goes on, because the increased surface slope down-stream of the hump causes a local increase in the flow rate. The quantitative analyses by Weertman and Nye include this term, but only as part of a linearized small-perturbation theory. However, it seems reasonable to conjecture that its effects will be 
broadly similar in a theory of the present type, which is of course essentially non-linear. Diffusion can be expected to cause sharp shock fronts to decay rapidly, and will exert a generally stabilizing influence. It seems unlikely to suppress instabilities entirely.

MS. received I 8 January 1971 and in revised form 20 May 197 I

\section{REFERENCES}

Greenberg, H., and Daou, A. 1960. The control of traffic flow to increase the flow. Operations Research, Vol. 8, No. 4, p. $524-3^{2}$.

Lighthill, M. J., and Whitham, G. B. 1955[a]. On kinematic waves. I. Flood movement in long rivers. Proceedings of the Royal Society, Ser. A, Vol. 229, No. 1178 , p. 28I-316.

Lighthill, M. J., and Whitham, G. B. 1955[b]. On kinematic waves. II. A theory of traffic flow on long crowded roads. Proceedings of the Royal Society, Ser. A, Vol. 229, No. 1178, p. 31 7-45.

Meier, M. F., and Post, A. S. 1969 . What are glacier surges? Canadian Journal of Earth Sciences, Vol. 6, No. 4, Pt. 2, p. $807-17$.

Newell, G. F. 1962. Theories of instability in dense highway traffic. Fournal of the Operations Research Society of Japan, Vol. 5 , No. 1, p. 9-54.

Newell, G. F. 1965 . Instability in dense highway traffic: a review. (In Almond, J., ed. Proceedings of the second International Symposium on the Theory of Road Traffic Flow [London, 1963]. Paris, Organization for Economic Cooperation and Development, p. 73-83.)

Nye, J. F. 1960. The response of glaciers and ice-sheets to seasonal and climatic changes. Proceedings of the Royal Society, Ser. A, Vol. 256 , No. 1287, p. $559^{-84}$.

Nye, J. F. 1963 . Theory of glacier variations. (In Kingery, W. D., ed. Ice and snow; properties, processes, and applications: proceedings of a conference held at the Massachusetts Institute of Technology, February 12-16, 1962 . Cambridge, Mass., M.I.T. Press, p. 151-6I.).

Paterson, W. S. B. 1969. The physics of glaciers. Oxford, etc., Pergamon Press. (The Commonwealth and International Library. Geophysics Division.)

Weertman, J. 1958. Traveling waves on glaciers. Union Géodésique et Géophysique Internationale. Association Internationale d'Hydrologie Scientifique. Symposium de Chamonix, $16-24$ sept. 1958, p. 162-68. 